\title{
Política de estabilização de renda para a agricultura familiar: uma análise de risco
}

\author{
Maria Aparecida Silva Oliveira ${ }^{1}$ \\ Erly Cardoso Teixeira²
}

Resumo: Os produtores familiares foram prejudicados pelas políticas de substituição de importações e de modernização da agricultura, sofrendo com elevadas transferências de renda para fora do setor. Uma forma de ressarci-los seria implementando uma política de estabilização de renda que asseguraria rentabilidade estável aos produtores. O objetivo deste artigo é determinar os benefícios de uma política de estabilização de renda implementada na agricultura familiar para agricultores e consumidores de arroz, feijão, milho e mandioca, e os custos para agricultores comerciais nesses mercados. Utilizou-se o modelo de Newbery e Stiglitz, que considera a redução do risco com a política de estabilização de renda. A política implicaria aumento de receita para produtores familiares. Os benefícios de transferência superariam os de eficiência para produtores familiares e consumidores. Os benefícios para a agricultura familiar superariam os custos da agricultura comercial com a política nos mercados de feijão, mandioca e milho, e os benefícios totais superariam os custos totais nos mercados de feijão e milho, ao contrário ocorreria nos mercados de arroz e mandioca,

\footnotetext{
${ }^{1}$ Doutoranda em Economia Aplicada na Universidade Federal de Viçosa. Professora do Departamento de Economia da Universidade Regional do Cariri - URCA, Crato -CE. e-mail: cida730@yahoo.com.br. Endereço: Departamento de Economia Rural - UFV, CEP: 36570-000.

${ }^{2}$ Ph.D., Professor Titular da Universidade Federal de Viçosa. e-mail: teixeira@ufv.br. Endereço: Departamento de Economia Rural - UFV, CEP: 36570-000.
} 
embora neste fosse pequena a diferença. Conclui-se que a implementação da política seria viável nos mercados onde a participação da agricultura familiar fosse maior que a da comercial e naqueles importadores.

Palavras-chave: estabilização de renda, agricultura familiar, risco.

Classificação JEL: Q12, Q18.

Abstract: Income transfers from family farm to nonagricultural sectors occurred due to imports to substitution policy. A way of compensating this segment could be compensated by an income stabilization policy that would improve the income distribution in the agricultural sector. Also it could assure a stable profitability to the farmers. The objective of this paper is to determine the benefits of an income stabilization policy implemented to the family farms producing rice, bean, corn and cassava. It is also objective of the research to determine the costs of this policy for commercial farmers. The methodology applies the Newbery's and Stiglitz's model, that considers the risk reduction with the income stabilization policy. This policy would increase income for the family farmers. The transfer benefits would overcome the efficiency benefits for family farmers and consumers. The benefits for the family farm would be larger than the costs for the commercial farm in the bean, cassava and corn markets. The benefits with this policy would overcome the costs in the bean and corn markets, but not in the rice and cassava markets.

Key words: income stabilization policy, family farm, risk.

JEL Classification: Q12, Q18.

\section{Introdução}

A adoção de uma política de estabilização de renda para a agricultura familiar seria uma forma de ressarci-la das perdas ocasionadas por sua exclusão do processo de modernização da agricultura brasileira.

O modelo de industrialização substitutivo de importação adotado no país, na década de 60, adiou a implantação de um grande parque agroin- 
dustrial no Brasil, o que resultou em grande crise de abastecimento de alimentos e levou o governo a rever o papel da agricultura no processo de desenvolvimento (COELHO, 2001).

A política adotada para re-inserir a agricultura nesse processo foi o crédito rural, que visava, principalmente, explorar o potencial exportador do setor. De acordo com SAYAD (1984), a eficácia do programa de crédito ficou comprometida, entre outros motivos, pela utilização de juros subsidiados. As taxas de juros cobradas, abaixo das taxas de mercado, eram compatíveis apenas com atividades de menor risco, o que levava os agentes financeiros a conceder maior parcela do crédito aos agricultores que oferecessem expressivo montante de garantia real e alto índice de liquidez.

Em virtude desse fato, os produtores comerciais, de modo geral, tiveram acesso ao crédito rural subsidiado e, ao se capitalizarem, promoveram a modernização parcial da agropecuária brasileira. Os produtores familiares, por outro lado, foram penalizados, visto que foram alvo de maiores distorções pela política adotada, sofreram com as elevadas transferências de renda para fora do setor e tornaram-se descapitalizados e tecnologicamente atrasados (FRANCO e TEIXEIRA, 1998).

De acordo com TEIXEIRA (2000), uma política de garantia de renda melhoraria a distribuição de renda no setor agrícola e asseguraria rentabilidade estável aos produtores, uma vez que eliminaria o risco de renda negativa na atividade. Assim, essa política impulsionaria a adoção de tecnologia e aumentaria a participação da agricultura familiar nos setores de insumo, produto e trabalho.

Alguns trabalhos já investigaram os efeitos de uma política de garantia de renda sobre a agricultura familiar. KAM-CHINGS e TEIXEIRA (1995) determinaram seus impactos nos preços e renda do segmento e nos custos e benefícios da política, aplicando o conceito de excedente econômico. FERREIRA, FIGUEIREDO e TEIXEIRA (1999) estimaram os benefícios para produtores e consumidores da aplicação do modelo de Newbery e Stiglitz. Contudo, esses trabalhos ignoraram os efeitos que a redução do preço do produto, decorrente dessa política, causaria na agricultura comercial.

O objetivo deste artigo é determinar os benefícios de uma política de estabilização de renda para os agricultores familiares e consumido- 
res de milho, feijão e mandioca, alimentos importantes na pauta de produção e consumo do país. A proposta de política de estabilização de renda, analisada neste trabalho, consiste na definição do preço-meta, calculado com base na média dos preços reais recebidos dos 60 meses anteriores. O recebimento do preço-meta seria garantido ao produtor familiar pelo governo, sempre que esse fosse superior ao de mercado. A contribuição adicional que se pretende dar, em relação às pesquisas anteriores, é considerar a questão do risco para produtores e consumidores na determinação dos benefícios da política e, ainda, determinar os custos para agricultores comerciais com sua implementação. Espera-se, assim, fornecer informações relevantes para os formuladores de política econômica sobre a proposta de política analisada.

Para classificar os produtores em agricultores familiares observaram-se as características necessárias para ser beneficiado pelo PRONAF (Programa Nacional de Fortalecimento da Agricultura Familiar). Os beneficiários do referido programa são aqueles que exploram parcela da terra na condição de proprietários, assentados, posseiros, arrendatários ou parceiros, e atendem simultaneamente aos seguintes quesitos: utilizam o trabalho direto seu e de sua família, podendo ter, em caráter complementar, até dois empregados permanentes e contar com a ajuda de terceiros, quando a natureza sazonal da atividade agropecuária assim o exigir; não detenham, a qualquer título, área superior a quatro módulos fiscais, quantificados segundo a legislação em vigor; tenham, no mínimo, $80 \%$ da renda familiar bruta anual originada da exploração agropecuária, pesqueira e/ou extrativa; e residam na propriedade ou aglomerado rural urbano próximo (PRONAF, 2004). Por conveniência em relação à disponibilidade dos dados, será utilizada a característica referente à área da propriedade para selecionar os agricultores familiares. Como um módulo fiscal corresponde, em média, a 25 ha, será considerada agricultura familiar aquela em que a propriedade tenha, no máximo, 100 ha.

A seguir, é apresentado o referencial teórico e analítico utilizado no artigo. Posteriormente, são apresentados e discutidos os resultados obtidos e as conclusões do trabalho. 


\section{Metodologia}

A política de estabilização de renda consiste na determinação, pelo governo, de um preço-meta acima do preço de mercado. Como a política seria destinada à agricultura familiar, e o preço-meta seria estabelecido, haveria estímulo a aumentar a produção nesse segmento. Considere o preço de equilíbrio inicial $\mathrm{P}_{0}$, dado pelo mercado, e o preço-meta $\mathrm{P}_{1}$, como representado na Figura 1 (a). Ao novo nível de preço, a quantidade ofertada pela agricultura familiar seria igual a $Q_{1}$. Dada a elasticidade da demanda, por essa quantidade os consumidores pagariam $\mathrm{P}_{2}$, menor que o preço inicial $\mathrm{P}_{0}$. A diferença entre $\mathrm{P}_{1}$ e $\mathrm{P}_{2}$ seria paga pelo governo aos agricultores familiares, com propriedade até 100 ha. Mediante essa política, esses produtores receberiam um benefício equivalente à área $\mathrm{P}_{1} \mathrm{CAP}_{0}$. Para a agricultura comercial, a política implicaria um custo, pois agora seus produtores receberiam $\mathrm{P}_{2}$ em vez de $\mathrm{P}_{0}$, passando a ofertar $\mathrm{Q}_{2}$, como indicado na Figura 1 (b). A perda de excedente do produtor para esse segmento equivaleria à área $\mathrm{P}_{0} \mathrm{~A}^{\prime} \mathrm{C}^{\prime} \mathrm{P}_{2}$.

Dada a redução de preço e dado o aumento de oferta da agricultura familiar, os consumidores obteriam um ganho dado pela área $\mathrm{P}_{0} \mathrm{ABP}_{2}$, como pode ser verificado no lado (a), da Figura 1. Além deste, com a redução de preço, os consumidores ganhariam o equivalente à perda da agricultura comercial, mostrado no lado (b), da mesma figura. Haveria, então, transferência de renda desse segmento para os consumidores. Entretanto, com a redução da oferta da agricultura comercial, os consumidores também sofreriam uma perda. Devido à dificuldade de captar o último efeito, considera-se que esse ganho para o consumidor seja igual a zero, ou seja, a transferência da agricultura comercial ocorrida pela redução de preço seria anulada pela perda devido à redução da oferta dos produtores comerciais. Todavia, para esses produtores haveria um custo que seria considerado parte do custo social da política.

Com a política, o governo teria um custo, representado pela diferença entre o preço pago pelos consumidores e o recebido pelos produtores familiares vezes a quantidade ofertada por esses produtores. Esse custo é representado, na Figura 1 (a), pela área $\mathrm{P}_{1} \mathrm{CBP}_{2}$. 


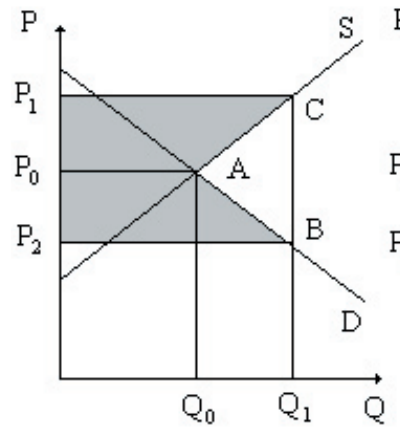

(a)

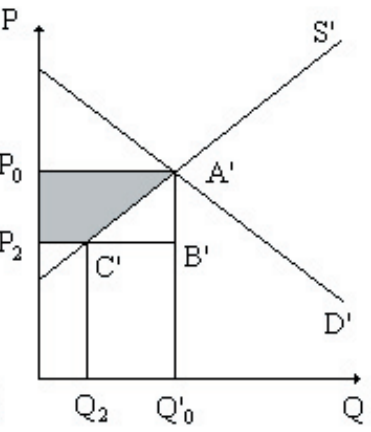

(b)

Figura 1 - Implicações da política de estabilização de renda para a agricultura familiar (a) e comercial (b).

Deduzidos do gasto com a política os benefícios para os produtores familiares e parte do benefício dos consumidores, obtida pelo acréscimo de oferta desse segmento e pela redução de preço, verifica-se, ainda, um custo social. De acordo com Wallace (1962), esse custo social da implementação da política seria calculado pela área do triângulo ABC.

A análise realizada até aqui considera a economia fechada. Entretanto, admitindo-se a existência de comércio internacional, outros efeitos da política de estabilização de renda poderiam ser captados. Observe os casos ilustrados na Figura 2, para a agricultura comercial. Essa ilustração, que se aplica tanto à agricultura familiar quanto à comercial, é realizada apenas para a agricultura comercial. O lado (a), da figura, mostra o caso em que, ao preço de mercado $\mathrm{P}_{0}$, há exportação do produto agrícola, pois a oferta é maior que a demanda. Como na análise anterior, ao ser estabelecido o preço-meta, o consumidor passaria a pagar $\mathrm{P}_{2}$ pelo produto, menor que o preço inicial. Como o produtor comercial não seria beneficiado pela política, passaria a receber $\mathrm{P}_{2}$ e teria uma perda equivalente à área $\mathrm{P}_{0} \mathrm{BDP}_{2}$. Essa perda seria dividida em duas partes; a área $\mathrm{P}_{0} \mathrm{ACP}_{2}$ representaria ganho para o consumidor, ou seja, haveria transferência da agricultura comercial para os consumidores, enquanto a área $\mathrm{ABCD}$ seria considerada um custo social da política, devido à perda da agricultura comercial.

Na Figura 2 (b) está ilustrado o caso em que haveria importação do produto ao preço de mercado $\mathrm{P}_{0}$. Ao ser estabelecido o preço-meta 
$\left(\mathrm{P}_{1}\right)$, que não seria oferecido aos produtores comerciais mas apenas aos familiares, haveria aumento na produção da agricultura familiar, o que permitiria, num primeiro momento, a redução das importações, e levaria a uma redução no preço internacional; assim, ao preço $\mathrm{P}_{2}$, a importação voltaria a aumentar. Ao pagar o preço $\mathrm{P}_{2}$, os consumidores obteriam um ganho equivalente à área $\mathrm{P}_{0} \mathrm{D}^{\prime} \mathrm{B}^{\prime} \mathrm{P}_{2}$. Para o produtor comercial haveria uma perda dada pela área $\mathrm{P}_{0} \mathrm{C}^{\prime} \mathrm{A}^{\prime} \mathrm{P}_{2}$, ou seja, também nesse caso seria transferida renda desse segmento para os consumidores. A área A'B'C'D' mostra o benefício social da política devido ao ganho do consumidor.

Um terceiro caso a ser considerado seria quando, com a implementação da política, o setor passasse de exportador a importador. Entretanto, nesse caso, o ganho do consumidor seria, aproximadamente, igual à perda do produtor comercial, e assim, se anulariam.
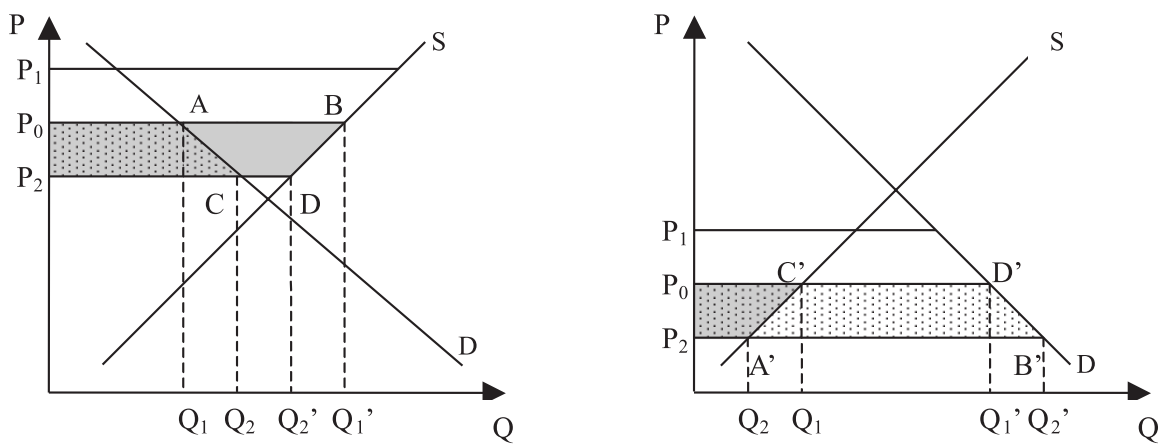

Figura 2 - Implicações da política de estabilização de renda na agricultura comercial com exportação (a) e com importação(b)

De acordo com NEWBERY e STIGLITZ (1985), a obtenção desses benefícios por produtores familiares e consumidores está relacionada também com a redução do risco ou com a segurança de renda obtida após a intervenção do governo. Essa análise será realizada apenas para agricultores familiares e consumidores dos mercados estudados.

Suponha que o produtor esteja sujeito a uma função de utilidade, de Von Neumann-Morgenstern U(Y), em que Y é renda aleatória, e as renda $\mathrm{Y}_{0}$ e $\mathrm{Y}_{1}$ representem a renda esperada com risco e a renda certa após a adoção da política, respectivamente. Segundo a teoria de riscos e incertezas, para livrar-se do risco, o produtor estaria disposto a pagar um prêmio B, 
mantendo o mesmo nível de utilidade. Esse prêmio representa, portanto, o benefício da política para o produtor, cuja solução é dada por

$$
E U\left(Y_{0}\right)=E U\left(Y_{1}-B\right)
$$

em que E denota a esperança. O valor do prêmio de risco pode ser obtido por aproximação, por meio da expansão por série de Taylor, de ambos os lados da expressão (1). O valor de B, geralmente, é expresso como proporção da renda, como mostrado a seguir:

$$
\frac{B}{\overline{Y_{0}}}=\frac{\Delta \bar{Y}}{\overline{Y_{0}}}-1 / 2 R \Delta c_{\bar{Y}_{i}}{ }^{2}
$$

em que $\bar{Y}_{i}$ é a renda média antes e depois da adocão da política, sendo, portanto, $\mathrm{i}=0,1 ; \Delta$, operador de diferença; $c_{\bar{Y}_{i}}{ }^{2}$, quadrado do coeficiente de variação de $\mathrm{Y}_{\mathrm{i}}$; e $\mathrm{R}$, coeficiente de aversão ao risco de Arrow-Pratt, dado por

$$
R(Y)=-Y \frac{U^{\prime \prime}(\bar{Y})}{U^{\prime}(\bar{Y})} .
$$

O primeiro termo do lado esquerdo da expressão (2) é o Benefício de Transferência (BT), obtido pelo aumento percentual da renda média com a adoção da política. Esse benefício independe do risco. O segundo termn é o Benefício de Eficiência (BE), que depende da variação do risco $\left(\Delta c_{\bar{Y}_{i}}{ }^{2}\right)$ e da intensidade de aversão ao risco (R). De acordo com a teoria de riscos e incertezas, o valor desse coeficiente seria nulo quando o indivíduo for neutro ao risco, e positivo, quando for avesso ao risco, sendo maior quanto maior for essa aversão. BRAVERMAN et al. (1992) consideraram $\mathrm{R}=1$ como um valor razoável de aversão ao risco.

$\mathrm{O}$ benefício para o consumidor $\left(\mathrm{B}^{\mathrm{c}}\right)$ pode ser obtido pela maximização da utilidade, sujeita à restrição da renda I, representado por

$$
\frac{B^{c}}{X}=\frac{1}{2}(1-\varepsilon) c_{P}^{2}+\left\{\frac{1}{2} \varepsilon c_{P}^{2}-R^{c} \rho(P, I) c_{I} c_{P}\right\},
$$

em que X é a média de gastos do consumo; ${ }^{c_{I}}$, coeficiente de variação da renda; $\rho(P, I)$ correlação entre preço e renda; e $R^{c}$, coeficiente de 
aversão ao risco de variação da renda do consumidor, dados os preços. Esse coeficiente é expresso por

$$
R^{c}=-I \frac{V^{\prime \prime}}{V^{\prime}},
$$

em que $V($. ) é a função indireta de utilidade do consumidor.

O primeiro termo do lado direito de (4) é o Benefício de Transferência do Consumidor $\left(\mathrm{BT}^{\mathrm{v}}\right)$. O primeiro termo entre colchetes é o Benefício de Arbitragem $\left(\mathrm{BA}^{\mathrm{c}}\right)$, que ocorreria se os consumidores fossem neutros ao risco $\left(\mathrm{R}^{\mathrm{c}}=0\right)$, e o segundo é o Benefício de Eficiência do Consumidor $\left(\mathrm{BE}^{\mathrm{c}}\right)$, que, como no caso do produtor, dependeria da extensão da variação do risco e da aversão ao risco.

\section{Operacionalização das variáveis e fonte dos dados}

A renda do produtor, antes da implementação da política de estabilização de renda, seria dada por

$$
Y_{0}=P_{0} \cdot Q_{0}
$$

Os valores de $\mathrm{P}_{0}$ e $\mathrm{Q}_{0}$ foram obtidos no site do IPEA e no AGRIANUAL (2001), no período de 1990 a 2000. A renda obtida, após a intervenção do governo, foi definida por

$$
Y_{1}=P_{1} \cdot Q_{1}
$$

em que $\mathrm{P}_{1}$ ou preço-meta foi calculado pela média dos últimos 60 meses, excluídos os anos de média mais alta e mais baixa, como recomendaram KAN-CHINGS e TEIXEIRA (1995). Os preços foram atualizados para dezembro de 2002, pelo IGP-DI disponível no site do IPEA. Os valores de $\mathrm{Q}_{1}$ e $\mathrm{Q}_{2}$ foram obtidos pela elasticidade da oferta e variações nos preços devidos à implementação da política; $\mathrm{P}_{2}$ foi calculado de forma igual, considerando-se, porém a elasticidade da demanda.

Como proxy da renda do consumidor foi utilizado o PIB per capita, obtido no site do IPEA. Os dados de consumo foram obtidos do AGRIANUAL (2001). 
Os valores das elasticidades da demanda utilizados foram calculados em outros trabalhos. As elasticidades-preço da demanda de feijão, milho, mandioca e arroz, iguais a $-0,32,-0,90,-0,10$ e $-1,60$, e da oferta de feijão, mandioca e arroz, iguais a 0,15, 0,09 e 0,57 respectivamente, forma retiradas de KAN-CHINGS e TEIXEIRA (1995). A elasticidade da oferta de milho, igual 0,27, foi obtida de MARQUES e AGUIAR (1993).

\section{Resultados}

No período analisado, o preço-meta da mandioca foi menor que o de mercado, nos anos de 1995 a 1997. Nos anos de 1999 e 2000, isso ocorreu no mercado de milho; nos de 1994 e 1998, no de feijão; e nos de 1991, 1998 e 1999, no de arroz. Nesses anos, portanto, não haveria intervenção governamental no mercado desses produtos, uma vez que os preços de mercado posicionados acima do preço-meta, isto é, além da média dos últimos 60 meses dos preços reais recebidos, garantiriam a renda para os produtores. Em virtude disso, esses anos foram excluídos da análise.

O preço-meta médio para o feijão seria estabelecido no valor de $\mathrm{R} \$$ $1,69 / \mathrm{kg}$, tendo o preço médio de equilíbrio de mercado, no período, sido de $\mathrm{R} \$ 1,33 / \mathrm{kg}$. O consumidor pagaria por esse produto o valor de $\mathrm{R} \$ 1,17 / \mathrm{kg}$. Com essa margem entre preço pago pelo consumidor e recebido pelo produtor igual a $\mathrm{R} \$ 0,52 / \mathrm{kg}$, sendo coberta pela política, o governo teria um gasto médio anual de $\mathrm{R} \$ 1.084,14$ milhão, e os produtores familiares, um acréscimo de receita de 32,92\%, como mostram as Tabelas 1 e 3 .

Para o produtor familiar de mandioca, a diferença entre preço recibo e preço pago pelo consumidor seria igual a $\mathrm{R} \$ 0,04 / \mathrm{Kg}$, o que implicaria acréscimo de receita de $22,71 \%$. O custo da política para o governo, com esse produto, seria de $\mathrm{R} \$ 778$ milhões.

No mercado de milho, o preço recebido pelo produtor familiar seria superior ao pago pelo consumidor, de $\mathrm{R} \$ 0,08 / \mathrm{kg}$, com a implementação da política de estabilização de renda. Isso representaria um aumento na receita, para esses produtores, de $25,85 \%$ e um gasto, para o governo, de $\mathrm{R}$ \$ 1.234,81 milhão. 
Tabela 1 - Preços/kg (em R\$) e variação percentual da receita do produtor familiar (média do período de 1990 a 2000)

\begin{tabular}{lcccc}
\hline & Arroz & Feijão & Mandioca & Milho \\
\hline Preço-meta & 0,57 & 1,69 & 0,15 & 0,38 \\
Preço de mercado & 0,47 & 1,33 & 0,13 & 0,32 \\
Preço ao consumidor & 0,44 & 1,17 & 0,11 & 0,30 \\
Variação percentual na receita do produtor & 34,11 & 32,92 & 22,71 & 25,85 \\
\hline
\end{tabular}

Fonte: Cálculos da pesquisa

No caso do arroz, a diferença entre o preço-meta e o pago pelo consumidor seria igual a $\mathrm{R} \$ 0,13 / \mathrm{kg}$. O pagamento dessa margem ao produtor familiar implicaria aumento de $34,11 \%$ na sua receita e custo de R 424 milhões para o governo.

A Tabela 2 mostra os benefícios para produtores familiares e consumidores e seus respectivos prêmios de risco, que, como explicitado na metodologia, representam os benefícios totais com a política. Como podem ser observados, os benefícios de transferência seriam mais significativos que os de eficiência, para produtores e consumidores. Isso indica que o efeito da política de estabilização de renda se daria de forma mais contundente por meio do mecanismo de transferência e, de forma mais branda, pelos fatores relacionados com o risco. O benefício de eficiência com valor negativo implicaria aumento no coeficiente de variação da renda dos produtores familiares de mandioca, milho e arroz e, portanto, maior risco com a implementação da política. Entretanto, como esses valores foram muito próximos de zero, pode-se considerar que não houve variação no risco.

Os benefícios para os consumidores seriam maiores que os dos produtores familiares, nos mercados dos quatro produtos analisados. $\mathrm{O}$ maior prêmio encontrado para produtores familiares foi o do mercado de arroz, o que implica que este é o que apresentou maior risco, entre os analisados. Os produtores familiares desse produto estariam dispostos a pagar um prêmio de $34,64 \%$ de sua renda inicial para obter renda certa ou segura. Para os consumidores, esse valor foi igual a 50,77\% do valor do dispêndio com o consumo do produto. Os prêmios pagos nos demais mercados foram iguais a $33,78 \%$ e $50,89 \%$, no caso do feijão; $26,44 \%$ e $50,85 \%$, no caso do milho; e iguais a $22,18 \%$ e $50,00 \%$, no mercado da mandioca para o produtor familiar e consumidor desses produtos, respectivamente. 
Tabela 2 - Prêmio de risco para consumidores e produtores familiares com a política de estabilização de renda - 1990 a 2000

\begin{tabular}{|c|c|c|c|c|}
\hline Benefícios & Arroz & Feijão & Mandioca & Milho \\
\hline Benefício de transferência & 0,3496 & 0,3376 & 0,2333 & 0,2655 \\
\hline Benefício de eficiência ${ }^{1}$ & $-0,0032$ & 0,0002 & $-0,0115$ & $-0,0011$ \\
\hline Benefício total do produtor $^{1}$ & 0,3464 & 0,3378 & 0,2218 & 0,2644 \\
\hline Benefício de transferência & 0,4882 & 0,4937 & 0,4950 & 0,4836 \\
\hline Benefício de arbitragem & 0,0118 & 0,0063 & 0,0050 & 0,0164 \\
\hline Benefício de eficiência $^{2}$ & 0,0077 & 0,0089 & 0,0000 & 0,0086 \\
\hline Benefício total do consumidor $^{2}$ & 0,5077 & 0,5089 & 0,5000 & 0,5086 \\
\hline
\end{tabular}

Fonte: Cálculos da pesquisa.

${ }^{1}$ Considerando $\mathrm{R}=1$. $\quad{ }^{2}$ Considerando $\mathrm{R}^{\mathrm{C}}=1$.

Por serem produtos básicos da dieta alimentar brasileira, o arroz, o feijão, o milho e a mandioca são bens de demanda inelástica, e variações nos seus preços, associadas à possibilidade de redução de oferta, implicariam um risco para os consumir, o que justifica o elevado prêmio de risco que os consumidores estariam dispostos a pagar.

Os demais custos e benefícios da política de estabilização de renda, nos mercados analisados, estão nas Tabelas 3, 4 e 5. Embora a margem de preços a ser coberta pelo governo tenha sido inferior para o milho, em relação ao feijão, a elevada quantidade ofertada tornaria mais altos os custos da política para o governo, com a produção de milho. Em volume ofertado, a mandioca apresentaria maior valor, entretanto, o preço-meta ficaria próximo ao preço pago pelo consumidor, o que faria com que o custo da política de estabilização de renda fosse menor que o de milho e de feijão. O menor custo da política para o governo seria no mercado de arroz, embora a margem de preços coberta tenha sido maior que as de mandioca e milho. Isso ocorreria porque a quantidade ofertada referente à agricultura familiar, nesse mercado, seria inferior às de mandioca e milho.

$\mathrm{Na}$ análise dos efeitos da política sobre a agricultura comercial, o mercado de arroz foi exportador em todo o período analisado. Já o mercado de milho, em 1995, passou de exportador a importador e foi importador nos demais anos. Em 1997, o mercado de feijão foi exportador; em 1992 e 2000, passou de exportador a importador; e nos outros anos da série, foi importador. Como a comercialização internacional da mandioca é pequena, considerou-se como mercado fechado, mesmo para análise da agricultura comercial. 
Os custos da agricultura comercial seriam maiores, no caso do arroz, e menores, no caso da mandioca, devido à participação dos dois tipos de produtores na oferta dos produtos analisados. Embora a oferta de arroz seja representativa na agricultura familiar $(29 \%)^{3}$, a produção, em sua maior parte (71\%), é proveniente da agricultura comercial. Como esses produtores não foram beneficiados pela política de estabilização de renda, os custos, para esse segmento, tornaram-se relativamente mais elevados. O mesmo ocorreu no mercado de milho, cuja participação da agricultura familiar é de $44 \%$. Como a oferta da mandioca é, em sua maioria, devida à agricultura familiar (85\%), o custo da agricultura comercial, nesse mercado, seria o menor entre os analisados. A agricultura familiar também é predominante na oferta de feijão (71\%), porém em menor proporção que na oferta de mandioca, o que implicaria custos maiores para a agricultura comercial produtora do primeiro produto em relação ao segundo.

O maior benefício da política ocorreria no mercado de milho, igual a R\$ 1.755,69 milhão (Tabela 3). Desse valor, 69,47\% seria de benefício para o produtor familiar e o restante para o consumidor. Nesse mercado, o custo da política para o agricultor comercial seria de $\mathrm{R} \$ 241,49$ milhões, menor que o benefício do produtor familiar (Tabela 4). O custo da agricultura comercial, somado ao do governo na implementação da política, faria com que o custo total no mercado de milho fosse o maior entre os analisados. Deve-se salientar que o fato de o mercado ter sido importador em, praticamente, todo o período analisado influencia esses resultados de custo e benefício. A condição de importador minimizaria o custo do produtor comercial, enquanto potencializaria o ganho do consumidor. Isso ocorreria, porque o custo originado da redução de preço, que ocorreria na agricultura comercial, seria transferido para os produtores dos países onde o produto seria comprado. Assim, como os consumidores consomem mais a preço menor (Figura 2(b)), haveria transferência de benefício desses produtores para os consumidores locais. Esse fato justifica o custo social negativo ou o benefício social que seria obtido nesse mercado com a implementação da política (Tabela 5).

\footnotetext{
${ }^{3}$ Os dados das participações dos segmentos familiar, propriedades de até 100 ha, e comercial, propriedades maiores que 100 ha, na produção são oriundos do Censo Agropecuário de 1995.
} 
Tabela 3 - Benefícios da política de estabilização de renda nos mercados de arroz, feijão, mandioca e milho - 1990 a 2000 - valores em mil R\$

\begin{tabular}{lcrrr}
\hline \multicolumn{1}{c}{ Benefícios } & Arroz & \multicolumn{1}{c}{ Feijão } & Mandioca & \multicolumn{1}{c}{ Milho } \\
\hline $\begin{array}{l}\text { (I) Benefício para produtores } \\
\text { familiares }\end{array}$ & $397.584,11$ & $880.603,91$ & $549.497,18$ & $1.219 .635,86$ \\
(II) Benefício para consumidores & $411.543,80$ & $590.597,74$ & $222.373,14$ & $536.051,84$ \\
\hline Benefício Total & $809.127,91$ & $1.471 .201,65$ & $771.870,32$ & $1.755 .687,70$ \\
\hline
\end{tabular}

Fonte: Cálculos da pesquisa.

(I) = área $\mathrm{P}_{1} \mathrm{CAP}_{0}$ Figura $1(\mathrm{a})$.

$(\mathrm{II})=$ área $\mathrm{P}_{0} \mathrm{ABP}_{2}$ Figura $1(\mathrm{a})+$ área $\mathrm{P}_{0} \mathrm{ACP}_{2}$ Figura $2(\mathrm{a})+$ área $\mathrm{P}_{0} \mathrm{D}^{\prime} \mathrm{B}^{\prime} \mathrm{P}_{2}$ Figura $2(\mathrm{~b})$.

Efeitos semelhantes ao do mercado de milho ocorreriam no de feijão. Nesse mercado, seria obtido o segundo maior benefício da política, porém a participação do produtor familiar de feijão seria proporcionalmente menor que no caso do milho, igual a 59,86\% (Tabela 3). O benefício para a agricultura familiar de feijão (Tabela 3 ) superaria o custo para a agricultura comercial (Tabela 4). A participação do custo do governo no custo total da política seria de $87,61 \%$, devido ao baixo custo gerado pela política para a agricultura comercial nesse mercado. A condição de importador em, praticamente, todos os anos analisados proporcionaria a transferência de benefício dos produtores externos para os consumidores internos; assim, o custo do produtor comercial local de feijão seria minimizado. Dessa forma, também nesse mercado, seria obtido benefício social da política de estabilização de renda para a agricultura familiar (Tabela 5).

Tabela 4 - Custos da política de estabilização de renda nos mercados de arroz, feijão, mandioca e milho - 1990 a 2000 - valores em mil R\$

\begin{tabular}{lcrrr}
\hline \multicolumn{1}{c}{ Benefícios } & Arroz & \multicolumn{1}{c}{ Feijão } & Mandioca & \multicolumn{1}{c}{ Milho } \\
\hline $\begin{array}{l}\text { (I) Custo para o governo } \\
\text { (II) Custo para produtores }\end{array}$ & $424.057,58$ & $1.084 .142,63$ & $778.443,93$ & $1.108 .809,48$ \\
comerciais & $770.831,17$ & $153.333,17$ & 0,00 & $241.497,67$ \\
\hline Custo Total & $1.194 .888,75$ & $1.237 .475,80$ & $778.443,93$ & $1.350 .307,15$ \\
\hline
\end{tabular}

Fonte: Cálculos da pesquisa.

(I) = área $\mathrm{P}_{1} \mathrm{CBP}_{2}$ Figura $1(\mathrm{a})$.

(II) $=$ área $\mathrm{P}_{0} \mathrm{ACP}_{2}$ Figura 2(a) + área $\mathrm{P}_{0} \mathrm{C}^{\prime} \mathrm{A}^{\prime} \mathrm{P}_{2}$ Figura 2(b)

O benefício total gerado pela política, para o mercado de mandioca, seria de R\$ 771,87 milhões, 71,19\% dos quais seriam referentes ao benefício da agricultura familiar (Tabela 3). Como já exposto, na análise desse mercado considerou-se a não-existência de comércio internacional. Nessa análise, o custo da agricultura comercial seria transferido ao consumidor, convertendo- 
se em um ganho. Entretanto, devido à perda que o consumidor incorreria com a redução de oferta do segmento comercial, o ganho se anularia. Por isso, o custo do produtor comercial, nessa análise, não é contabilizado, e o custo total da política deve-se ao gasto do governo. Obviamente, nesse tipo de análise, o custo total supera o benefício total ${ }^{4}$, havendo, portanto, um custo social com a política. Entretanto, o custo social seria pequeno nesse caso, equivalendo a apenas $0,84 \%$ do custo total da política (Tabela 5).

No mercado de arroz, o benefício total da política seria de $\mathrm{R} \$ 809,13$ milhões, mas, nesse caso, a participação do consumidor seria equivalente à do produtor familiar (Tabela 3). A participação do último seria de $49,14 \%$ do benefício total. Nesse mercado, o custo da agricultura comercial superaria o benefício para a agricultura familiar, por dois motivos: primeiro, devido à maior participação da agricultura comercial no mercado de arroz, o que faria com que a proporção de produtores beneficiados fosse menor que a de penalizados com a política; segundo, o mercado de arroz seria exportador em todo o período analisado, e, contrário ao que ocorre no caso de importação, mediante a exportação, os produtores locais transfeririam benefícios para os consumidores externos, potencializando os custos da agricultura comercial. Esse custo representaria $64,51 \%$ do custo total da política. No mercado do arroz, o custo total da política superaria o benefício total, havendo um custo social igual a R\$385,76 milhões (Tabela 5).

Tabela 5 - Benefícios e custos da política de estabilização de renda nos mercados de arroz, feijão, mandioca e milho - 1990 a 2000 - valores em mil R\$

\begin{tabular}{lcrrr}
\hline \multicolumn{1}{c}{ Custos e benefícios } & Arroz & Feijão & Mandioca & \multicolumn{1}{c}{ Milho } \\
\hline Custo Total & $1.194 .888,75$ & $1.237 .475,80$ & $778.443,93$ & $1.350 .307,15$ \\
Benefício Total & $809.127,91$ & $1.471 .201,65$ & $771.870,32$ & $1.755 .687,70$ \\
\hline Custo Social & $385.760,84$ & $-233.725,85$ & $6.573,61$ & $-405.308,55$ \\
\hline
\end{tabular}

Fonte: Cálculos da pesquisa

Pelos casos analisados, pode-se perceber que a política de estabilização de renda para a agricultura familiar tende a ser viável nos casos em que a participação desse segmento é consideravelmente maior que a da agricultura comercial no mercado, e nos casos em que, com a implementação da política, o mercado seja importador. Dessa forma, a implementação da

\footnotetext{
${ }^{4} \mathrm{~A}$ área $\mathrm{P}_{1} \mathrm{CBP}_{2}$ é maior que a soma das áreas $\mathrm{P}_{1} \mathrm{CAP}_{0}$ e $\mathrm{P}_{0} \mathrm{ABP}_{2}$ na Figura $1(\mathrm{a})$.
} 
política seria viável nos mercado de feijão e milho, visto que os benefícios totais superariam os custos totais (Figuras 1(a), 1(b) e 2(b)), e os setores obteriam custos sociais negativos, o que equivaleria a benefícios sociais, e seria inviável no caso do arroz, em que o contrário ocorreria. No mercado de mandioca, em que não há importação ou exportação, pode-se considerar viável a implementação da política, mesmo havendo um custo social, pois esse seria pequeno em relação ao benefício gerado.

\section{Conclusões}

A política de estabilização de renda para a agricultura familiar traria implicações para produtores comerciais, familiares e consumidores. Ao analisar a implantação da política nos mercados de arroz, feijão, mandioca e milho, percebe-se que, nos quatro mercados, os produtores familiares teriam acréscimos de receita.

Os prêmios de risco dos produtores familiares foram maiores no mercado de arroz, o que mostra ser este o de maior risco. Em todos os mercados, tanto para produtores familiares quanto para consumidores, os benefícios de transferência seriam maiores que os de eficiência com a política.

Devido à maior participação da agricultura comercial na oferta de arroz (71\%), os custos para os seus produtores seriam elevados com a implementação da política. A menor participação da agricultura comercial na oferta de mandioca e feijão levaria à obtenção de efeito oposto a esse. A participação elevada desse segmento na produção do milho implicaria custos maiores para esses produtores, em relação aos de feijão e de mandioca. Entretanto, esses custos não superariam os benefícios para a agricultura familiar nos mercados de milho, mandioca e feijão, mas superariam os do mercado de arroz. Deve-se ressaltar que esse resultado seria encontrado, supondo a igualdade das elasticidades de oferta das agriculturas comercial e familiar para feijão, mandioca, milho e arroz.

Os benefícios para os produtores familiares seriam maiores que para os consumidores com a implementação da política nos mercado de feijão, mandioca e milho, ocorrendo o inverso no mercado de arroz.

Os produtores comerciais dos mercados importadores, milho e feijão, teriam seus custos minimizados pela implementação da política, enquanto para o exportador, arroz, estes seriam potencializados. No mercado 
em que não haveria comercialização internacional, mandioca, o custo da agricultura comercial, que seria benefício para consumidores, seria anulado pela perda dos últimos, que ocorre com a redução da oferta do segmento comercial.

Haveria benefício social líquido nos mercados de milho e feijão e custo social líquido nos mercados de arroz e mandioca, se a política fosse posta em prática. Dessa forma, a política seria viável aos dois primeiros casos, mas não ao terceiro. Entretanto, no caso da mandioca, pode-se considerar que a política seria viável, pois o custo social gerado seria pequeno em relação ao custo total da política e aos benefícios gerados.

Assim, conclui-se que a política de estabilização de renda seria viável aos mercados em que a participação da agricultura familiar fosse superior à participação da agricultura comercial e aos mercados importadores. Dessa forma, a política de estabilização de renda para a agricultura familiar contribuiria para a promoção da agricultura brasileira, se fosse implementada nos mercados de feijão, milho e mandioca, e não no mercado de arroz.

\section{Bibliografia}

AGRIANUAL 2001. Anuário estatístico da Agricultura. São Paulo: FNP Consultoria e Comércio, 2001.

BRAVERMAN, A. et. Al. Costs and benefits of agricultural price stabilization in Brazil. Washington: The World Bank, 1990. (WPS, 564).

BRAVERMAN, A. et. Al. Commodity price stabilization and policy reform: an approachto evaluation of the brazilian price band proposals. Washington: The World Bank, 1992. 110p.

COELHO, C. N. 70 anos de política agrícola no Brasil (1931-2001). Revista de Política Agrícola, Brasília, ano X, n.3, p. 3-58, jul./set. 2001.

FERREIRA, A. V.; FIGUEIREDO, A. M. R.;TEIXEIRA, E. C. Custos ebenefícios de umprograma degarantia de renda aplicado ao PRONAF. RevistadeEconomiae Sociologia Rural, Brasília, vol. 37, n.2, p. 31-50, 1999.

FRANCO, J. M. C.; TEIXEIRA, E. C. Transferência de renda da agricultura comercial e familiar produtora de arroz, feijão e leite. Revista de Economia e Sociologia Rural, Brasília, v. 37, n. 1, p. 57-75, jan./mar., 1999. 
INSTITUTO DE PESQUISA ECONÔMICA APLICADA - IPEA. Séries históricas. [8 mar. 2004]. (http: \\www.ipeadata.gov.br).

KAM CHINGS, M. H. F. L., TEIXEIRA, E. C. Política de garantia de renda e equivalência em produto: análise comparativa de custos e benefícios. Revista de Economia e Sociologia Rural, Brasília, v. 33, n. 1, p. 23-36, jan./mar., 1995.

PROGRAMA NACIONAL DE FORTALECIMENTO DA AGRICULTURA FAMILIAR - PRONAF. Perguntas e Resposta. [7 nov. 2004]. (http: \\www. pronaf.gov.br).

MARQUES, P. V.; AGUIAR, D. R. D. de. Comercialização de Produtos Agrícolas. São Paulo: Editora da Universidade de São Paulo, 1993. 295p.

NEWBERY, D. M. G.; STIGLITZ, J. E. The theory of commodity price stabilization: a study in the economics of risk. New York: Oxford University Press, 1985. $426 \mathrm{p}$.

TEIXEIRA, E. C. Política de Garantia de Renda. In: SANTOS, M. L. e VIEIRA, W. C. (Editores) A agricultura na virada do milênio: velhos e novos desafios. Viçosa, 2000.

SAYAD, J. Crédito rural no Brasil. São Paulo: FIPE/Pioneira, 1984. 125p.

WALLACE, T. O. Measure of social costs of agricultural programs. Journal of Farm Economics. V.44. p. 580-94, may, 1962. 